International Review of Research in Open and Distributed Learning

Volume 17, Number 1

January - 2016

\title{
Factors of Participants and Blogs that Predict Blogging Activeness During Teaching Practice and Induction Year
}

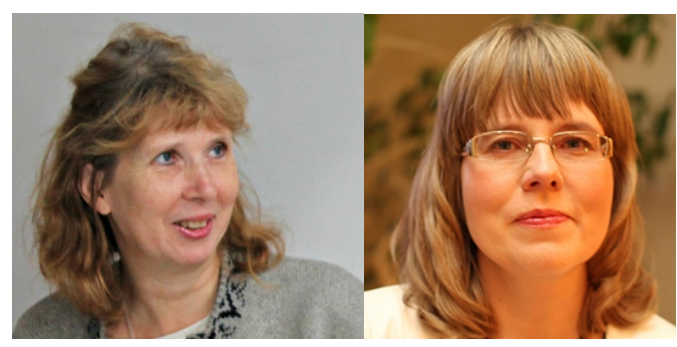

Piret Luik and Merle Taimalu

University of Tartu, Estonia

\begin{abstract}
The blog as a type of social software has been used in education for several years, and its positive effect in the field has been asserted in many studies. This study presents the factors of participants and blogs that predict blogging activeness during teaching practice and induction year. During the teaching practice and induction year all participants could use a blog to share experiences, ask questions, receive support, and so on. The blogs were supported by the tutors and all blogs were collective blogs, but they were organised differently and used differently. The data collected included 1,137 blog posts from 192 participants using 13 collective blogs along with their self-reports via pre- and post-period questionnaires. Multiple regression analysis was used in this study. The results showed that the most influential positive factors predicting participant activeness on the blog were the strength of social relationships between the participants and the pleasant and supportive atmosphere in the blog so that learners can feel blogging is suitable.
\end{abstract}

Keywords: blog; teacher education; distance learning; collaborative learning 


\section{Introduction}

To become a teacher the deep integration of theory and practice is needed. During the teaching practice in Estonia student teachers observe the others and give their own lessons. Newly qualified teachers during the induction year work at their own schools with a mentor and meet only four times per year with the other newly qualified teachers. According to the management of student-teacher practice in Estonia, student teachers are allotted to different schools as individuals or in groups of up to five. The distance between different schools often exceeds two hundred kilometres. Even if they are grouped in the same school, their separate schedules give them few opportunities to meet. The situation is even worse in the case of induction year teachers who are completely alone in their schools. In that way some beginning teachers are isolated from their former course mates, but sharing feelings and thoughts is important for supporting beginning teachers (Capa Aydin \& Woolfolk Hoy, 2005).

Usually, student teachers and newly qualified teachers have to complete a certain number of hours in the field and write a reflection piece or present their observations in seminars. They have limited time during the seminars to exchange ideas, and the experiences they accumulate is difficult to hand down to the next seminar. But learning from each other is becoming more and more important (Williams \& Jacobs, 2004). Although there are course management systems, we needed therefore a tool that could archive the student teachers' and newly qualified teachers' postings, categorize articles, and enable the teachers to respond to each other's postings. We chose blogs to fill such a purpose, because blogs are a growing trend in Estonian education. Still the question arose, which characteristics of beginning teachers determine the blogging activeness and in which collective blogs beginning teachers are more active in blogging.

\section{Literature Review}

Education in the 21st century demands more attention be paid to the use of information communication technology (ICT) to promote learning. ICT facilitates not only learning in the classroom but also outside the classroom and the sharing of knowledge. During the last decade blogging has emerged and spread as a convenient option for communicating and building virtual communities of special interest (Agarwal, Liu, Tang, Yu, 2012). Sim and Hew (2010) have defined blogs (or weblogs) as "personal webpages, or home pages" which have typically four features: "individual ownership, hyperlinked post structure, updates displayed in reverse chronological order, and archival of postings" (p. 152). Herring, Scheidt, Bonus, and Wright (2004) see blogs as on a continuum between standard Web pages and asynchronous CMC. Nardi, Schiano and Gumbrecht (2004) see blogs as radio shows. But blogs can be seen also as internet-based diaries that facilitate interactive computer-mediated communication through text, picture, audio and video (Agarwal et al, 2012; Dearstyne, 2005), can also involve links to other blogs or web pages (Agarwal et al, 2012), and have the potential to learn through your own blog and those of others (Kaplan, 2012). However, a diary was usually a private place, which connotes confidentiality, but blogs as electronic diaries are publications composed for at least some audience (Li, 2005). 
According to $\mathrm{Li}$ (2005), there are seven main motivations (reasons) for blogging: selfdocumentation, improving writing, self-expression, medium appeal, information, passing time, and socialization (p. 130).

During recent years, several kinds of social software have been applied more frequently in education. According to Sim and Hew's (2010) review about the use of blogs in higher education setting, in teacher education blogs are most frequently used as compared with other disciplines (e.g., science, language, business, etc).

In a blog created for educational purposes (also called an edublog), students or educators can use blogs for different purposes, e.g., as learning journal or knowledge log, or for recording personal everyday life, for expression emotions/feelings, for communication with others, or as assessment or task management tool (Sim \& Hew, 2010, p. 154). Participants can also read and comment on what other blog users have written (Cakir, 2013; Luik, Votri, Taimalu, \& Kalk, 2011). In teacher education, blogs are good tools for documenting the learning process and the development of teachers-to-be because of the opportunity to look back at your own writings (Yang, 2009). Blogging is a process that includes many aspects: writing, reading, reflecting, questioning, and commenting, and hence, a blog can provide several pedagogical benefits (Can \& Ozdemir, 2006), which have an important role in active knowledge construction (Andergassen, Behringer, Finlay, Gorra, \& Moore, 2009) and knowledge sharing with other learners (Halic, Lee, Paulus, \& Spence, 2010). Besides learning outcomes, blogging can also have an effect on affective domain (Sim \& Hew, 2010).

Blogs can be divided into several types. Krishnamurthy's (see Herring, Scheidt, Bonus, \& Wright, 2004) classification is based on two dimensions (personal versus topical, and individual versus community) which divide blogs into four types. A personal blog can be, for example, an online diary; in a topical blog, an individual or group deals with some content creation. In the individual blog, the owner is the main person who writes the blog, or initiates and leads the discussions. In a community (collective) blog, many individuals have the possibility to participate and to initiate topics or discussions (Agarwal et al, 2012). "Personal blogs are much like newspaper columns authored by single commentator while community blogs resemble magazines with approved contributors" (Li, 2005, p. 52). Nardi et al. (2004) have discussed the privacy aspect of blogs in three levels, from the most private blog protected with a password to the most public blog which can be easily found by search engines.

Nowadays, the importance of collective learning, learning from each other, and collaboration have been emphasized more and more, and the significance of professional learning communities is supported because of the positive effect they have on teaching practice and learner achievement (Vescio, Ross, \& Adams, 2008). Blogs are one way to create and support such learning communities. On account of this, the use of collective blogs has increased in education. In addition to supporting information exchange and sharing knowledge, the posts in a collective blog offer feedback (Ndon, 2010), which is crucial in the learning process. However, students collaborating in a collective blog might be less interested in blogging than learners in individual blogs (Kim, 2008), because there are two types of students: individually-oriented, who dislike 
blogging, and community-oriented, who blog with enthusiasm (Can \& Ozdemir, 2006). Furthermore, studies have found that while the majority of students reported blogging as enhancing learning and providing a positive experience, few of them valued the comments from their peers (Halic et al, 2010).

Student engagement in the blog is influenced by several factors, both conducive and hindering. Deng and Yuen (2013) have divided hindering factors info four parts. Knowing these factors we can promote blogging. First are technological factors (computer and internet accessibility, perceived difficulty of blogging technology - comfortable with technology). Sometimes learners are afraid of using new technologies, but as Cakir (2013) affirms, blogs, as Web 2.o technologies, do not demand complex computer technical knowledge from the user, and therefore, even technically modestly skilled learners are able to participate in blogging. Second are pedagogical factors (purpose of blogging, why and what to write about, voluntary nature or forced writing, lack of assessment on the tasks in the blog) (Deng \& Yuen, 2013). Several studies underscore the importance of knowing the educational purpose and benefit of blogging (Cakir, 2013) - why use the blog (because of requirements or perceived value for communication with other bloggers). There has been discussion about whether blogging should be voluntary or compulsory, and whether learners are more motivated when the tasks on the blog are assessed or not. According to Deng and Yuen (2013), not assessing the tasks on the blog and voluntary blogging can be inhibiting factors, but Can and Ozdemir (2006) claimed that blog-use should not be compulsory and tasks on the blog should not be assessed. Third are individual factors (lack of time, preference for other media, uncertainty what to write about, blog's personal appropriateness or reluctance for certain individuals) (Deng \& Yuen, 2013). The demographic and individual characteristics of bloggers can also predict their engagement in a blog: age can be quite a good predictor for a person's blogging (Li, 2005), but gender or technical skills do not seem to be such good predictors (Cakir, 2013). Fourth are social factors (previous social relationships, the level of participation in the blog - are there enough writers online, other possibilities for face-to-face interaction) (Deng \& Yuen, 2013). In addition, motivation and level of challenge offered by blog use (Cakir, 2013) and the sense of community (Halic et al., 2010) can have an impact on blog use. Several blog characteristics have also been found to influence student engagement in blogging: attractive content, pleasant atmosphere on the blog, and blogging support (including quickly given comments and replies) (Huang \& Lo, 2012). Nardi, Schiano and Gumbrecht (2004) have analysed blogging as social activity. As a community, blogs can also have an important impact on relationships. Those can help create new relationships but also enhance existing ones (Agarwal et al, 2012). It is easier to write for audiences you are already familiar with. Knowing the blogger better makes the readers feel closer to the person behind the computer screen ( $\mathrm{Li}, 2005)$, and vice versa. Therefore, we can suppose that the previous relationships between blog members could also predict the engagement of blog participants. According to Andergassen and colleagues (2009), students' preferences for direct (online) communication and privacy concerns were mentioned as inhibiting factors. $\mathrm{Li}$ (2005) mentioned the importance of being active and updates on the blog being regular for the blog to stay "alive". 
Although many learners may have experience with individual blogging for their own pleasure, they need to receive more preparation to better understand the idea of blogging for educational purposes and what being a member of a learning community in a collective blog means (Deng \& Yuen, 2013).

As previous studies reveal, blogs, including collective blogs, are used in education. The individual characteristics of blog writers and how the community on a collective blog is formed might influence blogging activity. Therefore, the aim of this study was to present the factors of participants and blogs that predict blogging activeness during the teaching practice and induction year. The research questions was: Which characteristics of the participants and of the blogs predict how active they are on the blog?

\section{Method}

\section{Context of the Study}

The study was in the context of teaching practice and induction year. The settings of these two conditions can be described briefly. . Teaching practice lasts from 7 to 12 weeks, and it begins at different times depending on curriculum and university. Student teachers are distributed between the different schools and they have mentor-teachers from the school or kindergarten, who supervise their practice. Also a supervisor from the university visits the school/kindergarten and observes student teachers' practice. During the teaching practice student teachers have to observe lessons and conduct supervised lessons. Induction year activities starts at the end of September or at the beginning of October (depending on the university) and ends at the beginning of May. During the induction year newly qualified teachers have a mentor at their school and they meet also in the university with the other newly qualified teachers and the leader of a seminar group four times. They work at the schools and kindergartens as ordinary teachers, but they also get feedback and advice from their mentor, who observes their lessons, and during the seminars in universities they discuss the crucial incidents.

During the academic year 2010/11, the research team (four members, who had experience with blogging and who had acquainted themselves with the field) introduced the blogging environment to all student teachers and newly qualified teachers who were selected to the sample. They helped to create accounts in the Blogger (https://www.blogger.com) environment and helped those participants who had never used blogs to enter the first blog post. Collective blogs were used and all participants were divided between 13 blogs according to the university, the length of practice or induction year period, and the beginning time of practice/induction year. Participants were told that this environment is totally voluntary for them, but they were told about the possibilities offered by collective blogging. The blogs were used for reflecting and sharing their experiences. According to Krishnamurthy's (see Herring, Scheidt, Bonus, \& Wright, 2004) classification our blogs were topical (the topic was teaching practice/induction year) and community blogs. One tutor (the member of the research team) and in some cases the coordinator of practice also 
participated as a contributor to each blog. Her task was to support the participants, answer questions and solve emerging problems. Tutors were not active in the blog, they did not initiate discussions and did not give tasks. None of the tutors was the evaluator of practice or induction year. All participants were asked to blog voluntarily and to write about the topics they wanted to share with others or to ask questions. They were told that their mentor-teacher and university supervisors are not on the blog and the blog is not part of evaluation of their practice/induction year. In this way, the blog provided the opportunity to be connected with other pre-service teachers or induction year teachers and also receive advice from the tutor in a more practical way. All the blogs were password-protected.

\section{Sample}

The sample consisted of 192 participants (103 student teachers and 89 newly qualified teachers) who entered the induction year programme from the University of Tartu (64\%) and Tallinn University (36\%). These two universities are the two main institutions in Estonia providing teacher education. Eleven participants (6\%) were male. Student teachers and newly qualified teachers were from different educational stages and subjects. Sixty-three participants (33\%) were pre-school teachers or in pre-school teacher education, 41 participants (21\%) were primary-school teachers or studied that field, and 43 participants (83\%) were subject teachers. In addition, 5 special educationalists (3\%) participated in the study. Of the subject teachers 26 (31\%) were science teachers, 50 (60\%) teachers of humanities, and 7 (8\%) teachers of art and physical culture. The participants were selected so that the sample covered different subjects and schoollevels. The average age of the participants was $25.6(\mathrm{SD}=5.88)$ years (minimum 20 and maximum 51 years).

\section{Data Collection}

A total of 1,137 posts (628 new posts and 509 comments) from 13 blogs were used as the primary data source. To analyse the blog posts, a quantitative content analysis was used. The content analysis was conducted using a coding manual elaborated by three researchers. Agreement between the coders was at least $83 \%$ in all variables. How active participants were on the blog was defined by three characteristics. At first we defined the activeness in the blog by the number of posts, because we wanted the participants to write in the blog multiple times. The number of posts was counted as all new posts and comments written by a participant. Secondly we used as activeness characteristic the average length of posts in words, because it was important that they write more in depth, decribed the situation for others more precisely. The length of all posts was measured in terms of words and the average length of all posts by a participant was calculated. In some cases it might have happened that learners used the blog only sometimes and not during all practice/induction year. For that we used the third characteristic measuring the activeness of participants in the blog. It was the number of periods and it was found to be as follows: all blogging cycles were divided into seven periods. The number of periods when participant wrote in the blog was used as the number of the blogging period.

Characteristics of the blogs used were: 
- The average number of comments per new post on the blog.

- The percentage of blog posts consisting of communication with other participants. All posts where participants asked something from the others, replied to others' questions, reacted to some previous issue, added something to somebody's post from their side were considered posts consisting of communication with other participants.

- The percentage of blog posts where participants wrote about success. Words and phrases indicating success were, for example, "I was satisfied", "I succeeded", "I could manage", "My mentor was satisfied with me", etc.

- The percentage of blog posts where participants wrote about problems. Words and phrases indicating problems were, for example, "I couldn't manage with...", "I have problems with...", "My lesson was a disaster", etc.

- The number of participants in the blog varied from 5 to 24 .

- The number of participants in the blog who shared more than two posts varied from 2 to 23.

- Writing about what they expected from the teaching practice/induction year was set as an initial task in two of the 13 blogs.

- The strength of social relationships on the blogs varied and was defined on a 3-level scale: in 5 of the blogs they were not familiar with each other and did not meet each other outside the blog (the lowest strength), in 5 of the blogs the participants met in some seminars or in some courses (medium strength), and 3 of the blogs contained coursemates who also met each other outside the blog (the highest strength).

The characteristics of the participants were collected using pre- and post-questionnaires. Before blogging began, all participants filled in a pre-questionnaire, and after blogging, a postquestionnaire. The pre-questionnaires measured individual characteristics (sex, age), and a 5point Likert scale was used to measure evaluations of their computer skills and internet accessibility, previous blogging experience and Communication Style Scale (Warschauer, 1995/1996). The post-questionnaire measured evaluations of the blogging experience and perceived support outside the blog from course-mates and mentor-teacher. Perceived support outside the blog from course-mates and supervisors was measured using support items from the Teacher Interpersonal Self-Efficacy Scale (Emmer \& Hickman, 1991). All these measurements were also on a 5-point Likert scale.

\section{Data Analysis}


Summary indices (percentages, means, or medians) from the quantitative analysis of the blog posts were calculated for each participant as the first step in the data analysis. Then the data from the questionnaires were matched to the characteristics of the blogs and summary indices of the posts. The multiple regression analysis using a stepwise method was applied to see the degree to which characteristics of participants and blogs are related to the activeness in the blog. Because the first post could be created in the introduction seminar, only the date from the participant who wrote more than once in the blog was used in multiple regression analysis. A KolmogorovSmirnov Test was used for checking are the standardized residuals normally distributed.

\section{Results}

\section{Descriptive Statistics}

According to the pre-questionnaire, 69 participant (35\%) had blogging experience. The average number of new posts per participant was 4.05 ( $\mathrm{SD}=7.59)$, the average number of comments per participant, $3.27(\mathrm{SD}=9.60)$, and the average total number of posts, $7.33(\mathrm{SD}=15.81)$. The average length in words of new posts was 120.42 ( $\mathrm{SD}=128.32)$, and the average length in words of comments, 78.86 ( $\mathrm{SD}=444.90)$. On average, the number of comments per new posts was .65 $(\mathrm{SD}=1.01)$.

Twenty-six of the participants (13.5\%) did not visit the blog during the teaching practice or induction year according to the data from the post-questionnaires. Six participants did not post anything in the blogs, but according to their answers in the post-questionnaire they visited the blog, read the posts and reflected on these. Eighty-four participants (44\%) marked in the postquestionnaire that they did not comment on others' posts in the blog, but they did so in their mind.

Eighty-five participants (44\%) wrote more than once in the blog. Of these, 33 (39\%) had previous blogging experience. Because the distribution of the postings was strongly skewed to the left (Table 1), log transformation was used for regression analysis. The natural logarithm of the number of postings and average length of postings was calculated as two new variables, which were used in regression analysis.

\section{Table 1}

Frequencies of postings of those participants who wrote more than one posting

\begin{tabular}{lcc}
\hline $\begin{array}{l}\text { Interval of the number } \\
\text { of postings }\end{array}$ & Frequency & Percentage \\
\hline $2-3$ & 31 & 37 \\
$4-9$ & 23 & 27 \\
$10-20$ & 19 & 22 \\
More than 20 & 12 & 14
\end{tabular}




\begin{tabular}{lll}
\hline Total & 85 & 100 \\
\hline
\end{tabular}

\section{Characteristics of Participants and Blogs Related to Participant Blogging Activeness}

The results (Table 2) indicate that five characteristics explain $47.5 \%$ of the total variance of the number of posts with $\log$ transformation.

Table 2

Multiple regression analysis on number of posts with log transformation

\begin{tabular}{|l|l|l|l|r|r|r|}
\hline $\mathrm{R}^{2}$ & $\mathrm{~F}$ & Model & $\beta$ & $\mathrm{T}$ & Tolerance & VIF \\
\hline .475 & $13.565^{* *}$ & $\begin{array}{l}\text { Evaluation on Blogging } \\
\text { was suitable' }\end{array}$ & .444 & $4.523^{* *}$ & .910 & 1.099 \\
\hline & $\begin{array}{l}\text { Strength of social } \\
\text { relationships between } \\
\text { the participants in the } \\
\text { blog }\end{array}$ & .338 & $3.436^{* *}$ & .902 & 1.108 \\
\hline & $\begin{array}{l}\text { Evaluation on own } \\
\text { computer skills }\end{array}$ & .217 & $2.311^{*}$ & .99 & 1.008 \\
\hline & $\begin{array}{l}\text { Percentage of blog posts } \\
\text { consisting of } \\
\text { communication with } \\
\text { others }\end{array}$ & .210 & $2.130^{*}$ & .897 & 1.115 \\
\hline
\end{tabular}

${ }^{*} \mathrm{p}<.05{ }^{* *} \mathrm{p}<.01$

According to standardized regression coefficients, the significance of precursor variables on positive factors for the number of posts with log transformation are as follows: Evaluation 'Blogging was suitable', Strength of social relationships between the participants in the blog, Evaluation on own computer skills, and Percentage of the blog posts consisting of communication with others. VIF values were well below 10 (or alternatively, tolerance values are all well above 0.1) indicating no multicollinearity in the data (Field, 2009). Distribution of 
standardized residuals was not statistically significantly different from the normal distribution (with Kolmogorov-Smirnov Test statistic .093 p=.20).

In terms of predicting the length of the posts with log transformation, the results of the multiple regression analysis are presented in Table 3 . We arrived at a model with two variables explaining $15.2 \%$ of the total variance of the average length of posts. The age was a negative factor and the evaluation on 'Blogging was helpful during teaching practice/induction uear' was a positive factor for predicting the average length of posts with log transformation. Distribution of standardized residuals was not statistically significantly different from the normal distribution (with Kolmogorov-Smirnov Test statistic 0.10, $\mathrm{p}=.09$ ).

Table 3

Multiple regression analysis on average length of posts with log transformation

\begin{tabular}{|l|l|l|l|l|l|l|}
\hline $\mathrm{R}^{2}$ & $\mathrm{~F}$ & Model & $\beta$ & $\mathrm{T}$ & Tolerance & VIF \\
\hline .475 & $5.574^{* *}$ & Age & -.307 & $-2.617^{*}$ & .994 & 1.006 \\
\hline & $\begin{array}{l}\text { Evaluation on 'Blogging } \\
\text { was helpful during } \\
\text { teaching } \\
\text { practice/induction year' }\end{array}$ & .265 & $2.264^{*}$ & .994 & 1.006 \\
\hline
\end{tabular}

${ }^{*} \mathrm{p}<.05{ }^{* *} \mathrm{p}<.01$

In the final multiple regression analysis we used number of periods with log transformation as dependent variable. The results (Table 4 ) indicate that four characteristics explain $49.4 \%$ of the total variance in the number of blogging periods with log transformation. According to the standardized regression coefficients, the significance of precursor variables on positive factors for number of blogging periods with log transformation are as follows: Evaluation on 'Blogging was suitable', Strength of social relationships between the participants in the blog, and Evaluation on Internet access. The only negative factor was Percentage of blog posts about success. VIF values are well below 10 and tolerance values are both above 0.1 indicating no multicollinearity in the data. Distribution of standardized residuals was not statistically significantly different from the normal distribution (with Kolmogorov-Smirnov Test statistic 0.095, $\mathrm{p}=.20$ ).

Table 4

Multiple regression analysis on number of blogging periods with log transformation 
Factors of Participants and Blogs that Predict Blogging Activeness During Teaching Practice and Induction Year Luik and Taimalu

\begin{tabular}{|l|l|l|l|l|l|l|}
\hline $\mathrm{R}^{2}$ & $\mathrm{~F}$ & Model & $\beta$ & $\mathrm{T}$ & Tolerance & VIF \\
\hline .494 & $14.652^{* *}$ & $\begin{array}{l}\text { Evaluation on 'Blogging } \\
\text { was suitable }\end{array}$ & .416 & $4.453^{* *}$ & .967 & 1.034 \\
\hline & $\begin{array}{l}\text { Strength of social } \\
\text { relationships between the } \\
\text { participants in the blog }\end{array}$ & .471 & $4.72^{* *}$ & .859 & 1.164 \\
\hline & $\begin{array}{l}\text { Percentage of blog posts } \\
\text { about success }\end{array}$ &,- 315 & $-3.249^{* *}$ & .899 & 1.112 \\
\hline & $\begin{array}{l}\text { Evaluation on Internet } \\
\text { access }\end{array}$ & .225 & $2.423^{*}$ & .980 & 1.020 \\
\hline
\end{tabular}

${ }^{*} \mathrm{p}<.05{ }^{* *} \mathrm{p}<.01$

\section{Discussion and Conclusions}

In our study, we used topical and community blogs according to Krishnamurthy's (see Herring, Scheidt, Bonus, \& Wright, 2004) classification, which were totally voluntary and were not assessed. Less than half of the participants wrote at least two times in the blog. Surprisingly the proportion of participants who had previous blogging experience was almost the same in the whole sample and among those who wrote more than once in the blog. Thus, not all of those who had previous experience in blogging wanted to use blogs in these settings and some participants who were active bloggers had no previous experience with blogging.

Our aim was to find significant predictors for blogging activeness, and we used three different characteristics describing blogging activeness: the number and length of posts and the number of blogging periods (how many periods from all seven did participants blog). According to the regression analysis, we can say that all three independent variables can be predicted by the different characteristics of the blogs and the participants.

The most significant predictors seemed to be the two following: the strength of social relationships between the participants in the blog, and the evaluation that blogging was suitable, which both predicted participant blogging activeness in two cases: the number of posts and the number of blogging periods. The strength of social relationships between the blog members 
seems to be one of the most influential factors. These results are in concordance with Deng and Yuen's (2013) findings, who mentioned previous social relationships as important for learner engagement in a blog. Halic et al. (2010) have underscored that the sense of community in the blog positively affects participant blogging activeness. Social presence theory can also help to explain such results - interaction in web-based learning is influenced by student consciousness of the perception of other learners (Tu \& McIsaac, 2002).

All other predictors were different for different indicators of blogging activeness, and all of them were predictors only for the one characteristic describing blogging acitivity. The number of posts was also predicted by the percentage of blog posts consisting of communication with others and the evaluation on own computer skills. The number of blogging periods was predicted by the evaluation on Internet access, in addition to the above-mentioned two predictors. Deng and Yuen (2013) have also noted that technological factors (e.g., Internet access and comfort with technology) can have an impact on blogging activeness. Although Cakir (2013) underlines that blogs do not demand complex computer knowledge, in our study the participant's evaluation about their own computer skills seemed to have some impact on blogging activeness.

The average length of posts was predicted by the evaluation that blogging was helpful during teaching practice/induction year. Other educationalists have also pointed out the importance of a pleasant atmosphere in the blog, the personal appropriateness of the blog, and getting support from the blog, which can be seen as helpful (Deng \& Yuen, 2013; Huang \& Lo, 2012). In addition to the above-mentioned, the average length of posts was predicted also by the age of participant. As in our research, previous studies (e.g. Li, 2005) have also shown that age can be a predictor for an individual's blogging. According to our results, age was found to be a negative predictor (younger bloggers were more active). It is a quite-expected result, because older participants could think their computer skills were not as good as younger bloggers' or they did not feel themselves as comfortable as bloggers.

Finally, the number of blogging periods was predicted also by the precentage of blog posts about success, which was also a negative predictor. It is quite a surprising result. Maybe in the case of posts about problems or failure, other bloggers found it easier to write something comforting for the blog member, post something about their own similar experiences, give some advice, or write something in support. But in the case of posts about success, it could be more complicated to write something besides approval.

\section{Conclusions}

The characteristics of the participants and blogs predicted blogging activeness. The most significant predictors seemed to be the two following: the strength of social relationships between the participants in the blog, and the evaluation that blogging was suitable, which both predicted participant blogging activeness in two cases. All other predictors were different for different indicators of blogging activeness, and all of them were predictors only for the one characteristic describing blogging acitivity. 
If collective blogs are used during teaching practice or induction year, educationalists should pay attention to forming groups of participants and organizing the blogs. Strong social relationships between the participants seem to be one of the crucial aspects for ensuring participant blogging activeness, and also the pleasant and supportive atmosphere in the blog so that learners can feel blogging suitable and helpful to support them during learning process. Despite blog use being considered as not demanding complex computer technical knowledge from the user or previous experience, nevertheless learners' own evaluation about their computer skills can have an impact on blogging activeness.

In this study some essential characteristics of participants and blogs were presented, which may inform us about how to encourage the use of blogs, or what characteristics should be taken into consideration. So far, mostly blogs with specific learning tasks are investigated. In our study voluntary blogs in education were explored which could be considered valuable.

As the limitation of this study we can point out that the aim of the blog was limited. Only reflective blogs were used. Blogging was voluntary in our study and we did not use assessment. Other researchers have presented different positions, regarding voluntary blogs without assessment as not inspiring for blogging (Deng \& Yuen, 2013), or on the contrary, claiming that blogging should be voluntary and not assessed (Can \& Ozdemir, 2006). According to our research, we can suppose that in the case of a compulsory blog with assessment, we could have higher number and more active bloggers. The aim of our blogs was to support student/beginning teachers and to offer the possibility to communicate, share and learn from each other experiences, but not to perform specific learning tasks. Further studies should provide more information concerning the optimal values of the characteristics of the blog for use in education with different learning goals.

\section{References}

Agarwal, N., Liu, H., Tang, L., \& Yu, P. S. (2012). Modeling blogger influence in a community. Social Network Analysis and Mining, 2(2), 139-162.

Andergassen, M., Behringer, R., Finlay, J., Gorra, A., \& Moore, D. (2009). Weblogs in higher education - why do students (not) blog? Electronic Journal of e-Learning, 7(3), 203-215.

Cakir, H. (2013). Use of blogs in pre-service teacher education to improve student engagement. Computers \& Education, 68, 244-252.

Can, G. \& Ozdemir, D. (2006). Blogging in higher education: Theoretical and practical approach. Systemics, Cybernetics and Informatics, 4(6), 5-13.

Capa Aydin, Y., \& Woolfolk Hoy, A. (2005). What predicts student teacher self-efficacy? Academic Exchange Quarterly, 9(4), 123-128. 
Dearstyne, B. W. (2005). Blogs: The new information revolution? Information Management Journal, 39(3), 38-44.

Deng, L. \& Yuen, A. H. K. (2013). Blogs in pre-service teacher education: Exploring the participation issue. Technology, Pedagogy and Education, 22(3), 339-356.

Emmer, E. T. \& Hickman, J. (1991). Teacher efficacy in classroom management and discipline. Educational and Psychological Measurement, 51, 755-765.

Field, A. P. (2009). Discovering statistics using SPSS: And sex and drugs and rock ' $n$ ' roll. (3 ${ }^{\text {rd }}$ edition). London: Sage publications.

Halic, O., Lee, D., Paulus, T., \& Spence, M. (2010). To blog or not to blog: Student perceptions of blog effectiveness for learning in a college-level course. Internet and Higher Education, 13, 206-213.

Herring, S. C., Scheidt, L. A., Bonus, S., \& Wright, E. (2004). Bridging the gap: A genre analysis of weblogs. Proceedings of the 37th Hawaii International Conference on System Sciences, 111.

Huang, Y.-H. \& Lo, Y.-F. (2012). What makes blogging attractive to bloggers: A case of collegelevel constituency users. Journal of Computer Assisted Learning, 28, 208-221.

Kaplan, A. (2012). Blogs: Finding you voice, finding your audience. The Rosen Publishing Group, New York.

Kim, H. N. (2008). The phenomenon of blogs and theoretical model of blog use in educational context. Computers \& Education, 51, 1342-1352.

Li, D. (2005). Why do you blog: A uses-and-gratifications inquiry into bloggers' motivations. Master Thesis. Retrieved from http://commonsenseblog.typepad.com/common sense/ files/Li Dan Aug 2005.pdf

Luik, P., Voltri, O., Taimalu, M., \& Kalk, K. (2011). On the use of student teacher blogs during teaching practice. Procedia Social and Behavioral Sciences, 11, 165-169.

Nardi, B. A., Schiano, D. J., \& Gumbrecht, M. (2004). Blogging as social activity, or, would you let 900 million people read your diary? Proceedings of the 2004 ACM conference on Computer supported cooperative work, 222-231.

Ndon, U. T. (2010). Hybrid-context instructional model. The Internet and the classrooms: The way teachers experience it. Library of Congress Cataloging in Publication, United States of America. 
Sim, J. W. S. \& Hew, K. F. (2010). The use of weblogs in higher education settings: A review of empirical research. Educational Research Review, 5, 151-163.

Tu, C.-H. \& McIsaac, M. (2002). The relationship of social presence and interaction in online classes. The American Journal of Distance Education, 16(3), 131-150.

Vescio, V., Ross, D., \& Adams, A. (2008). A review of research on the impact of professional learning communities on teaching practice and student learning. Teaching and Teacher Education, 24, 80-91.

Warschauer, M. (1995/1996). Comparing face-to-face and electronic discussion in the second language classroom. CALICO Journal, 13(2\&3), 7-26.

Williams J., \& Jacobs, J. (2004). Exploring the use of blogs as learning spaces in the higher education sector. Australasian Journal of Educational Technology, 20, 232-247.

Yang, S. H. (2009). Using blogs to enhance critical reflection and community of practice. Educational Technology \& Society, 12(2), 11-21.

\section{Athabasca \\ University}

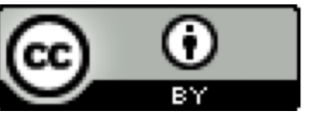

